\title{
Moment release budget at oblique convergence margin as revealed by the 2004 Sumatra-Andaman earthquake
}

\author{
Makiko Oishi* and Tamao Sato \\ Department of Earth and Environmental Sciences, Hirosaki University, Hirosaki, Aomori 036-8561, Japan
}

(Received November 27, 2006; Revised April 6, 2007; Accepted April 25, 2007; Online published August 31, 2007)

\begin{abstract}
Based on the model of oblique convergence, we predicted the slip rate on the megathrust plate boundary in the western Sunda arc and compared it with the slip distribution of the $2004 M_{\mathrm{w}} 9.0$ Sumatra-Andaman earthquake. The slip directions on the megathrust plate boundary, which are necessary for predicting the slip rate, were determined using the fault plane solutions of medium-sized earthquakes occurring for the last 30 years in the 2004 rupture zone. At long wavelengths the predicted slip rate correlates well with the latitudinal variation of the coseismic slip, suggesting that kinematics described by the model of oblique convergence operated over a long interseismic period and that the seismic coupling coefficient has been generally uniform along the strike of the rupture zone. Using the data for the same period of time, we estimated the total seismic moment released by the earthquakes on the Sumatra fault and its submarine continuation located on the backarc side of the Nicobar and Andaman islands. The ratio of the observed seismic moment to the seismic moment predicted from the model of oblique convergence is small. The residual may either be stored for generation of future earthquakes or was taken up by the fault creep at shallow depths.
\end{abstract}

Key words: Sumatra-Andaman earthquake, oblique convergence, oblique subduction, slip vector residual.

\section{Introduction}

On December 26, 2004, a great earthquake of $M_{\mathrm{w}} 9.0$ (HRV) nucleated off the northwestern Sumatra and propagated toward the Nicobar and Andaman islands, rupturing about 1500-kilometer segment of the boundary between the Indo-Australian Plate and the southeastern portion of the Eurasian Plate (Ammon et al., 2005; Lay et al., 2005). The rupture zone of the 2004 earthquake is characterized by a strong variation in the degree of oblique plate convergence (Fig. 1). Near the epicenter the plate convergence is roughly normal to the trench but almost parallel in the northern end of the rupture, the obliquity getting larger toward the north.

McCaffrey (1993) studied the mode of stress release at oblique subduction zones globally and showed that, for large obliquity zones, great earthquakes $\left(M_{\mathrm{w}}>8.0\right)$ nucleate where the deflections of slip vectors from the plate convergence vectors (acronymed SVR for slip vector residual) are smaller and plate convergence rates are faster. If we look at the 2004 rupture as consisting of multiple events that nucleated at places with different obliquity and SVR, its slip distribution along the strike of the trench provides data for studying the correlation among the magnitude of slip, obliquity and SVR. The coseismic slip of the 2004 rupture is largest off the northwestern Sumatra, decreasing gradually toward north (Ammon et al., 2005; Subarya et al., 2006).

*Now at Graduate School of Environmental Studies, Nagoya University, Furo-cho, Chikusa-ku, Nagoya City, Aichi, 464-8602, Japan.

Copyright (c) The Society of Geomagnetism and Earth, Planetary and Space Sciences (SGEPSS); The Seismological Society of Japan; The Volcanological Society of Japan; The Geodetic Society of Japan; The Japanese Society for Planetary Sciences; TERRAPUB.
At a first glance, the obliquity that increases from south to north appears to have a good correlation with the latitudinal variation of the coseismic slip. The slip directions of the 2004 rupture determined by seismic and geodetic data (Ammon et al., 2005; Tsai et al., 2005; Subarya et al., 2006) suggest that the SVR also has some connection with the latitudinal variation of the coseismic slip.

The western Sunda has been considered as providing the most convincing evidence for the model of oblique convergence first proposed by Fitch (1972). It says that a fraction of slip parallel to the plate margin can be taken up by transcurrent movements on a nearly vertical fault located on the continental side of a zone of plate consumption. The vertical faults in the western Sunda are the Sumatra fault and its submarine continuation located on the east side of the Nicobar and Andaman islands (e.g., Fitch, 1972; Curray et al., 1979; Curray, 2005; McCaffrey, 1991). With the advent of GPS, the kinematics of this region have been studied in more detail (Michel et al., 2000; Paul et al., 2001; Bock et al., 2003) and the model of the oblique convergence has been elaborated to investigate the internal deformation of the forearc block (McCaffrey et al., 2000; Genrich et al., 2000).

In the following, we first show how the model of oblique convergence relates the obliquity and SVR with the slip rate on the coupling megathrust plate boundary. Next we investigate the variation of SVR along the convergent plate margin using the fault plane solutions of medium-sized earthquakes occurring for the last 30 years in the 2004 rupture zone. Then we use the SVRs to predict the seismic-slip rate and compare it with the latitudinal variation of slip of the 2004 rupture. Finally, using earthquakes occurring during 


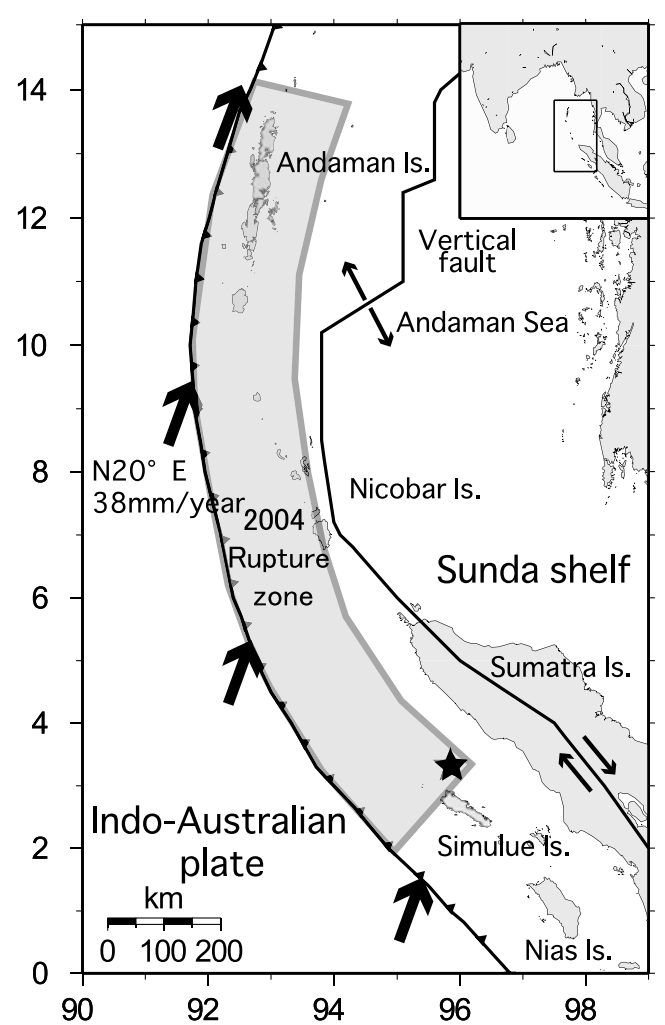

Fig. 1. Tectonic setting in and around the rupture zone of the 2004 Sumatra-Andaman earthquake. The trace of the Sumatra fault and its submarine continuation in the Andaman Sea is modified from Curray (2005). The plate convergence vector of the Indo-Australian Plate relative to the southeastern portion of the Eurasian Plate (Sunda Shelf) is taken from Subarya et al. (2006).

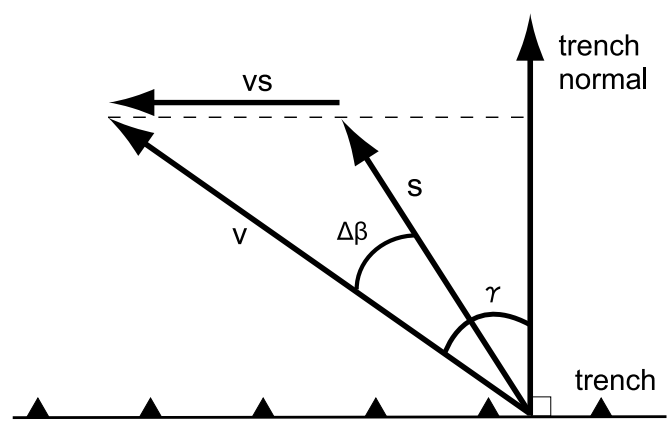

Fig. 2. Vector relations in the model of oblique convergence. $\gamma$ is obliquity and $\Delta \beta$ is SVR. $v$ is the plate convergence rate, $s$ the slip rate on the megathrust plate boundary, and $v_{s}$ the forearc slip rate.

the same period of time, we estimate the seismic-slip rate on the Sumatra fault and its submarine continuation in the Andaman Sea and compare it with the forearc slip rate predicted from the model of oblique convergence.

\section{Model of Oblique Plate Convergence}

The model of oblique convergence (Fitch, 1972; McCaffrey, 1991) states that a fraction of slip parallel to the plate margin is accommodated by transcurrent movements on a nearly vertical fault located on the continental side of a zone of plate consumption. In this model, the slip rate of the transcurrent movement, or the forearc slip rate, $v_{s}$, is expressed

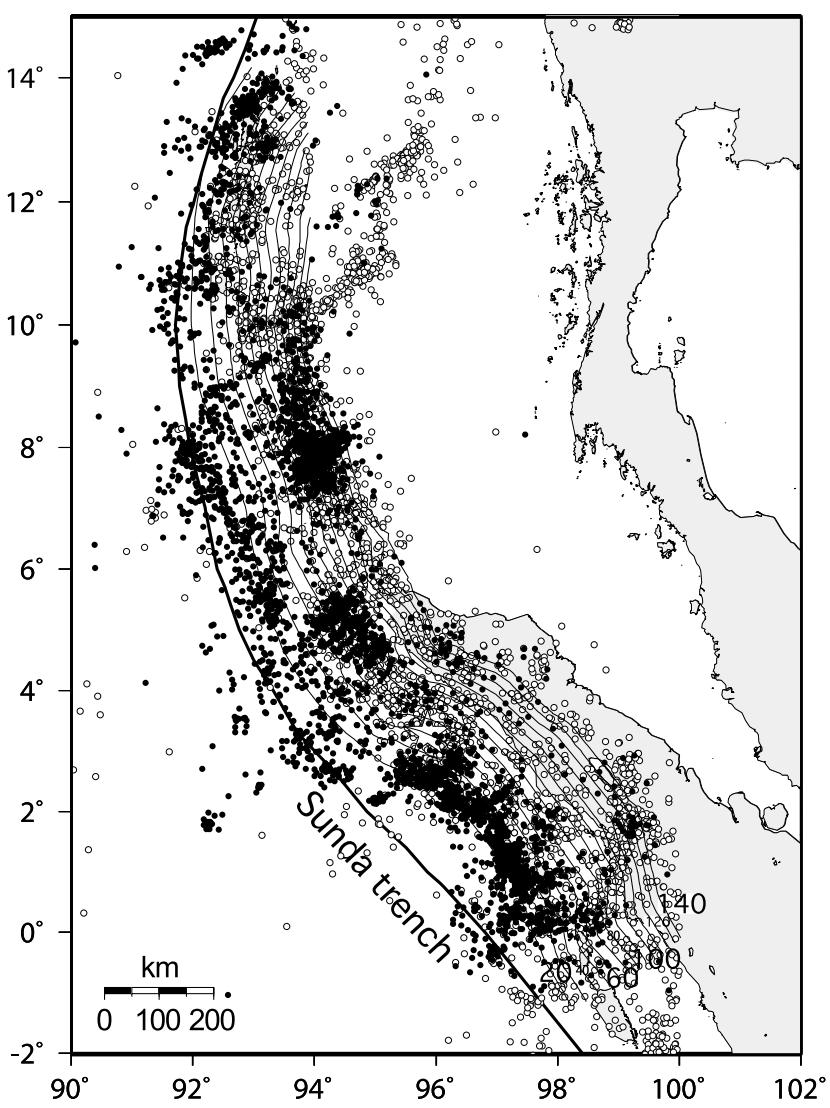

Fig. 3. Epicenter distribution of earthquakes occurring for the last 30 years from January 1976 through October 2005. Events are taken from the NEIC catalogue. The open circles denote the forefocks that occurred before the 2004 rupture and the solid circles indicate the aftershocks. The depth contours of the megathrust plate boundary are shown at every $10 \mathrm{~km}$.

by

$$
v_{s}=v \sin \gamma-s \sin (\gamma-\Delta \beta)
$$

where $v$ is the plate convergence rate, $\gamma$ the angle of obliquity, and $\Delta \beta$ the SVR (Fig. 2). Correspondingly, the slip rate on the megathrust plate boundary, $s$, is given by

$$
s=v \cos \gamma / \cos (\gamma-\Delta \beta)
$$

The seismic-slip rate on the megathrust plate boundary, $d$, is then defined by

$$
d=\eta s
$$

where $\eta$ denotes the seismic coupling coefficient. If we assume that the seismic coupling coefficient does not vary in the down-dip direction normal to the trench, the seismic moment rate per unit length along the plate margin, $\delta \dot{M}_{0}$, may be expressed by

$$
\delta \dot{M}_{0}=\mu \eta s W
$$

where $\mu$ is the rigidity and $W$ the width of the coupled part of the plate boundary along the down-dip direction. If we further assume the variables except $s$ to be constant along the plate margin, $\delta \dot{M}_{0}$ becomes simply proportional to the slip rate $s$ defined by (2). 

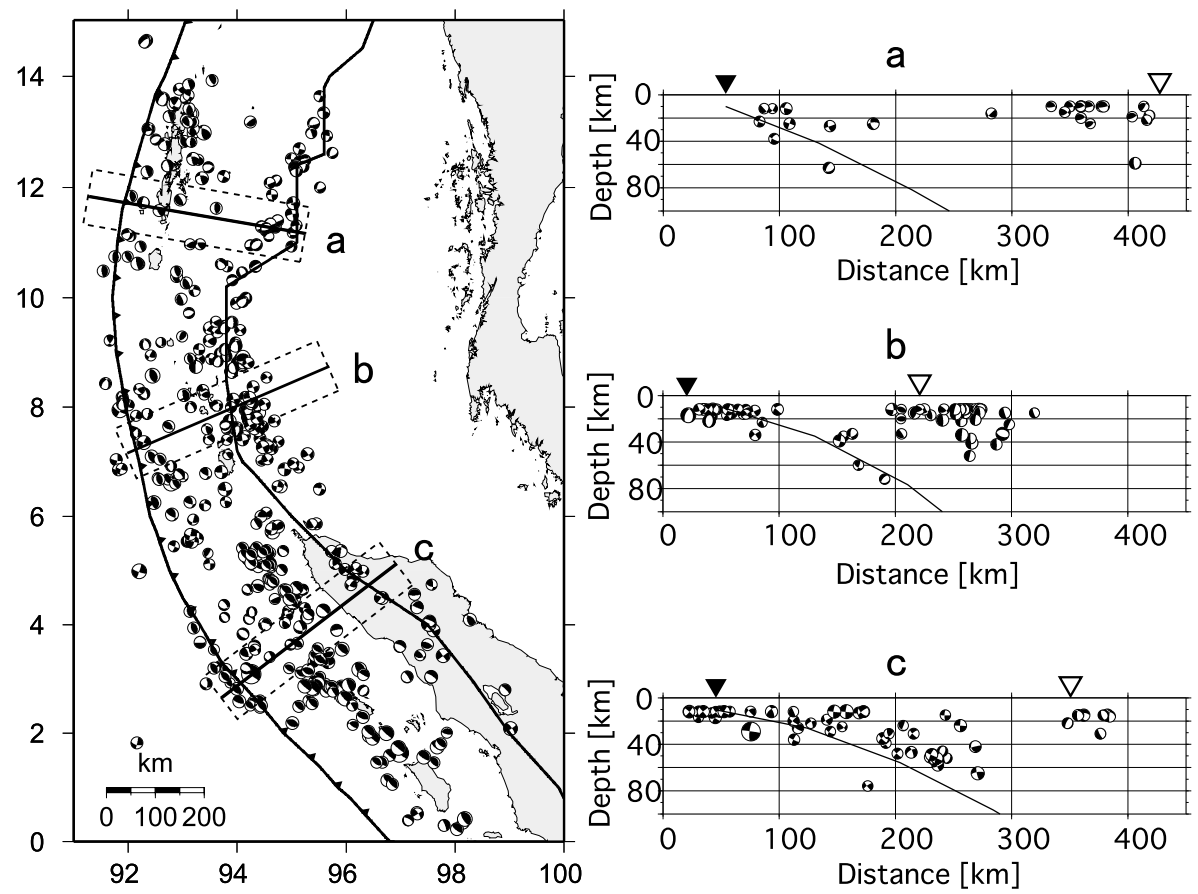

Fig. 4. Left: Epicenter distribution of 405 earthquakes used for the stress inversion. Mechanism diagrams follow equal area projection on the lower hemisphere. Right: Cross sectional views of the hypocenters for the three profiles indicated in the left. The solid lines indicate the locations of megathrust plate boundary. The solid and open triangles denote the locations of trench and vertical fault, respectively. The mechanism diagrams are projected on the background hemisphere.

Table 1. Parameters of inverted principal stresses for different groups of events. Stresses are positive for compression and $\sigma_{1}>\sigma_{2}>\sigma_{3} . \varphi$ : azimuth, $\theta$ : plunge, $\Phi=\left(\sigma_{2}-\sigma_{3}\right) /\left(\sigma_{1}-\sigma_{3}\right)$ : the ratio of the stress difference.

\begin{tabular}{|c|c|c|c|c|c|c|c|c|c|}
\hline \multirow{2}{*}{\multicolumn{3}{|c|}{ Groups $\quad$ Parameters }} & \multicolumn{2}{|c|}{$\sigma_{1}$} & \multicolumn{2}{|c|}{$\sigma_{2}$} & \multicolumn{2}{|c|}{$\sigma_{3}$} & \multirow[b]{2}{*}{$\Phi$} \\
\hline & & & $\varphi_{1}$ & $\theta_{1}$ & $\varphi_{2}$ & $\theta_{2}$ & $\varphi_{3}$ & $\theta_{3}$ & \\
\hline \multirow{7}{*}{$\begin{array}{l}\text { Mega- } \\
\text { Thrust } \\
\text { Plate } \\
\text { Boundary }\end{array}$} & \multirow{4}{*}{$\begin{array}{l}\text { After- } \\
\text { shock }\end{array}$} & Andaman & 254 & 28 & 156 & 16 & 40 & 57 & 0.37 \\
\hline & & Nicobar & 241 & 9 & 150 & 8 & 21 & 78 & 0.48 \\
\hline & & Sumatra-a & 224 & 10 & 134 & 1 & 38 & 80 & 0.49 \\
\hline & & Sumatra-b & 227 & 18 & 135 & 6 & 27 & 71 & 0.43 \\
\hline & \multirow{3}{*}{$\begin{array}{l}\text { Fore- } \\
\text { shock }\end{array}$} & Andaman & 249 & 4 & 340 & 21 & 150 & 68 & 0.63 \\
\hline & & Nicobar & 203 & 6 & 303 & 58 & 110 & 31 & 0.45 \\
\hline & & Sumatra & 205 & 39 & 303 & 10 & 45 & 49 & 0.69 \\
\hline \multirow{6}{*}{$\begin{array}{l}\text { Vertical } \\
\text { Fault } \\
\text { on the } \\
\text { Conti- } \\
\text { nental } \\
\text { Side }\end{array}$} & \multirow{3}{*}{$\begin{array}{l}\text { After- } \\
\text { shock }\end{array}$} & Nicobar & 212 & 65 & 17 & 24 & 109 & 6 & 0.59 \\
\hline & & Swarm & 19 & 12 & 230 & 76 & 110 & 7 & 0.65 \\
\hline & & Sumatra & 237 & 42 & 147 & 0 & 57 & 48 & 0.49 \\
\hline & \multirow{3}{*}{$\begin{array}{l}\text { Fore- } \\
\text { shock }\end{array}$} & Andaman & 357 & 81 & 230 & 6 & 140 & 8 & 0.89 \\
\hline & & Nicobar & 22 & 4 & 180 & 86 & 292 & 2 & 0.54 \\
\hline & & Sumatra & 2 & 10 & 124 & 72 & 269 & 15 & 0.34 \\
\hline
\end{tabular}

3. Stress Inversion of Medium-Sized Earthquakes

In order to confirm the validity of the model of oblique convergence, we investigate the mode of stress release of medium-sized earthquakes occurring for about 30 years (January 1976 through October 2005) in and around the rupture zone of the 2004 earthquake. Figure 3 shows the epicenter distribution of earthquakes compiled in the NEIC catalogue. Also shown is the configuration of the megathrust plate boundary that was determined using the hypocenter distribution of these earthquakes. We determined this configuration with the aid of the computer application tool (CHIKAKU DB) developed by Kanai et al. (2005). The depth contours indicate that the dip of the plate boundary gradually increases toward north.

We used the fault plane solutions of 405 medium-sized events compiled in the Harvard CMT catalogue (Dziewonski et al., 1981) (Fig. 4). We separated the events into two groups; i.e., the ones located on or close to the megathrust plate boundary (Fig. 5) and the others in the vicinity of the Sumatra fault and its submarine continuation in the Andaman Sea (Fig. 6). In order to find out a possible change in the stress filed at the time of a large earthquake, we further divided the events into those occurring before and after the 2004 earthquake. There are 198 foreshocks and 207 aftershocks. Figure 5 shows that the foreshocks are distributed in a deeper part relative to the aftershocks. In Fig. 6, we see that the aftershocks are concentrated in the Nicobar area $\left(7-10^{\circ} \mathrm{N}\right)$ whereas the foreshocks are spread over the Andaman, Nicobar, and Sumatra areas. Moreover, we divided the events into several subgroups considering the epicenter 

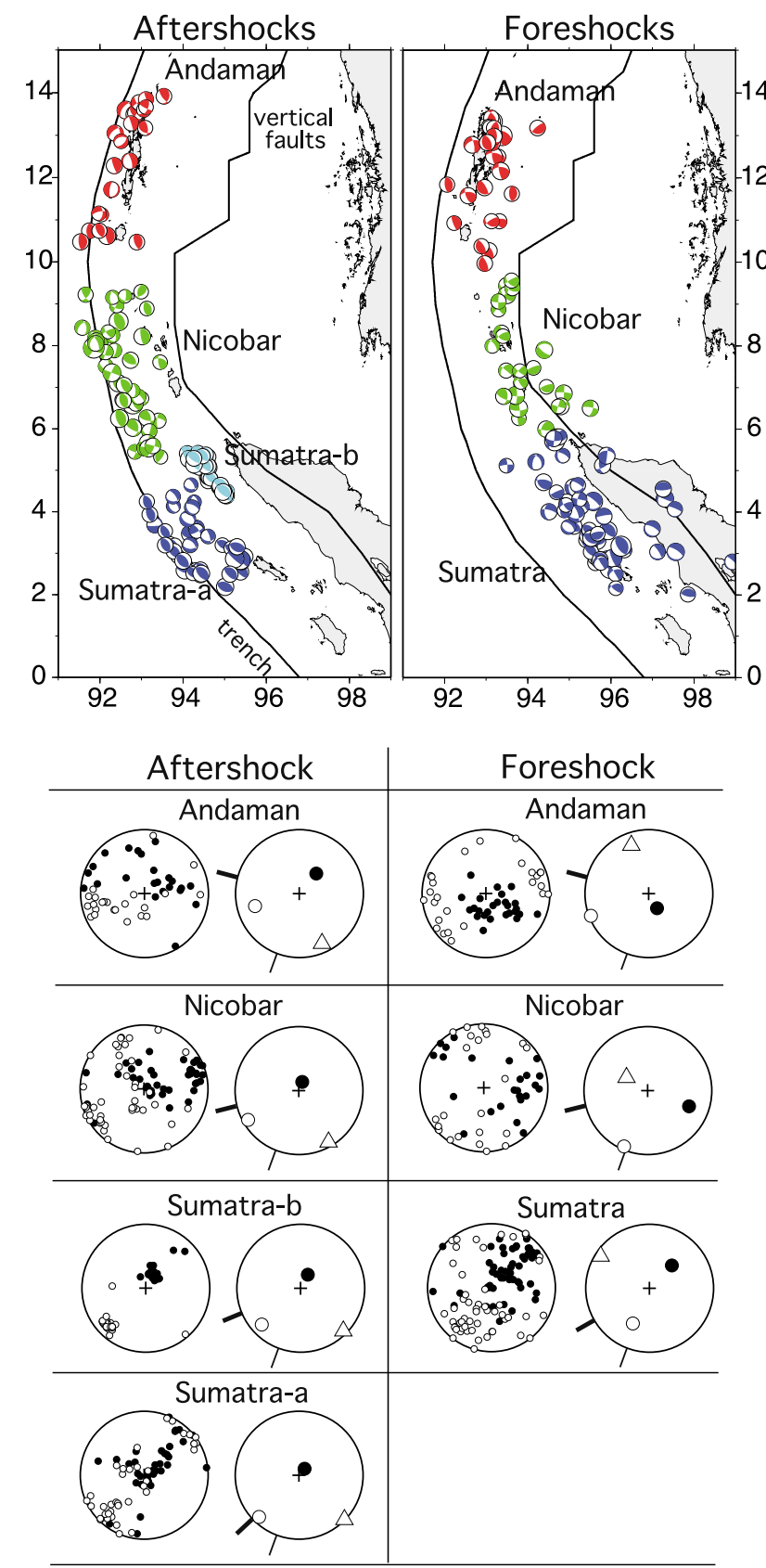

Fig. 5. Inverted principal stresses for groups of events located on the megathrust plate boundary. Upper shows the grouping of events. Lower shows the original data of $P$ and $T$-axes of the fault plane solutions and the inverted principal stresses determined with an allowable minimum value of the normalized value of $\operatorname{SSSC}(\omega)$ of 30 percents (Angelier, 2002). The open circles, triangles, and solid circles denote principal stresses $\sigma_{1}, \sigma_{2}$, and $\sigma_{3}$, respectively. Stresses are positive for compression and $\sigma_{1}>\sigma_{2}>\sigma_{3}$. Thin and thick tick marks attached on the circumference of the circles indicate the direction of plate convergence and the direction normal to the trench, respectively. Original data of $P$ and $T$-axes of the fault plane solutions are indicated by open and solid circles. Equal area projection on the lower hemisphere.

distribution of events along the plate margin. The swarm events during 25-29 January 2005 in the Nicobar area are separated into an independent group (Fig. 6).

We applied Angelier's (2002) method of stress inversion to each of the sub-divided groups. The inversion method determines a set of principal stresses that maximizes the sum of the shear stresses of slip components (SSSC) for a given

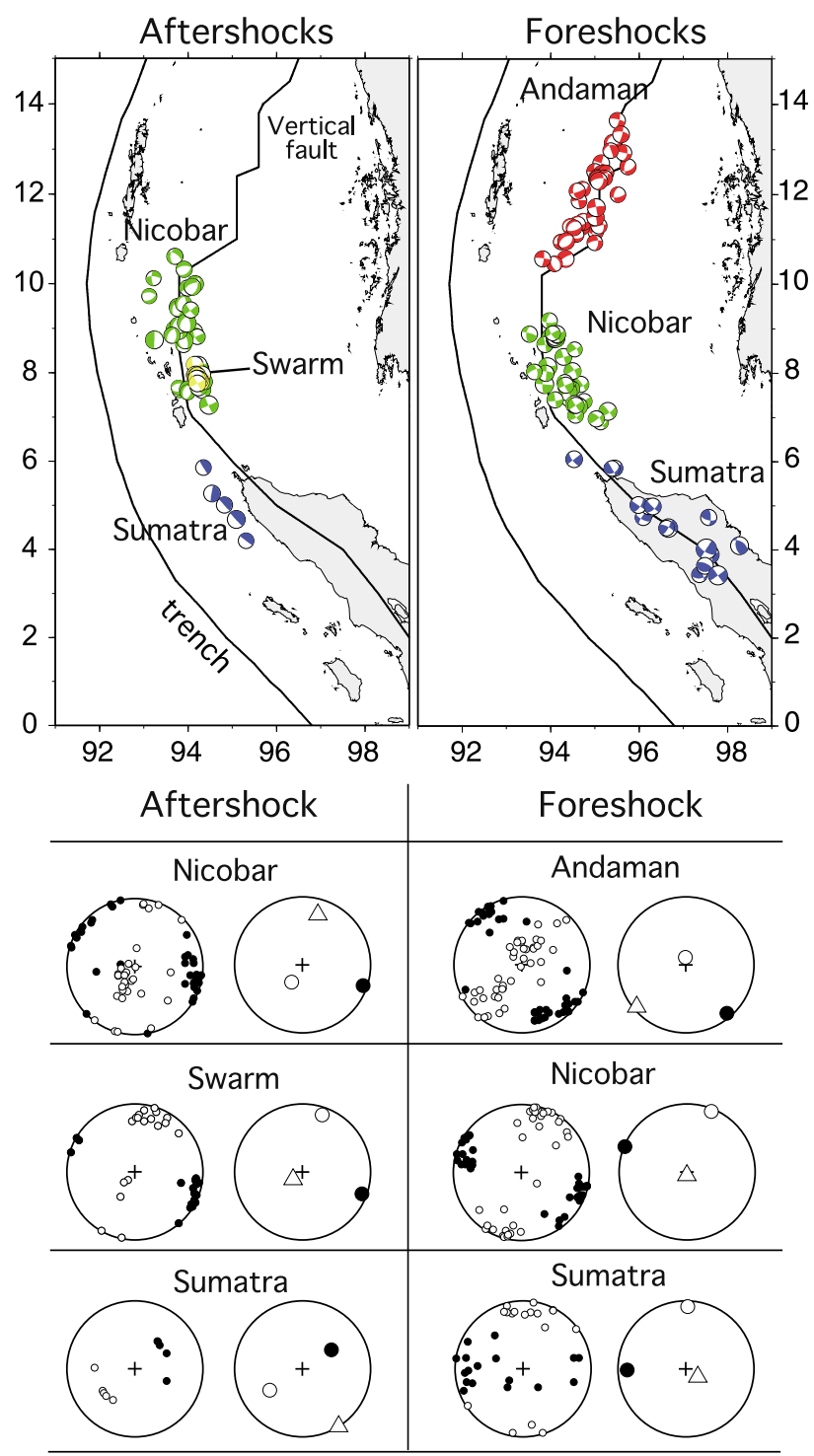

Fig. 6. Inverted principal stresses for groups of events in the vicinity of the vertical fault along the northwestern Sumatra fault and its submarine continuation in the Andaman Sea. The rest is the same as in Fig. 5.

set of fault plane solutions. We gave both nodal planes of an event as input data without choosing its fault plane. We excluded data that deviate significantly from the average trend by adjusting an allowable minimum value of the normalized value of $\operatorname{SSSC}(\omega)$. We started with using all events included in a group and discarded unfitted data by increasing the minimum value of $\omega$ by one percent at each step of iterative inversion (Angelier, 2002). The inverted stresses become stable for $\omega$ greater than about $30 \%$. The results obtained for $\omega=30 \%$ are shown in Figs. 5 and 6. Their numerical values are listed in Table 1 . For the groups of events on or close to the megathrust plate boundary, the directions of maximum compressional stresses fall between the normal to the trench and the direction of plate convergence (Fig. 5). Generally they trend more in the direction of the trench normal than in the direction of plate convergence. Except for the foreshock group in the Nicobar area, the stress regimes are of thrust-fault type in agreement with the underthrusting slip on the megathrust plate boundary. The stress regime in 
the Nicobar area is of strike-slip type. We suspect that the dataset includes events located away from the megathrust plate boundary because the stress regime is similar to the one for the swarm group in Fig. 6. In the Nicobar area, the earthquakes on the megathrust plate boundary and those on the vertical fault are located closer to each other than in the other areas (Fig. 4).

Strike-slip and normal fault types are characteristic of the inverted stress regimes for the groups in the vicinity of the Sumatra fault and its submarine continuation in the Andaman Sea (Fig. 6). Strike-slip types appear for the foreshock groups in the Sumatra and Nicobar areas as well as for the swarm activity in the Nicobar area. If we choose NW-SE or NNW-SSE trending plane as the fault plane, the slip assumes right-lateral sense that is consistent with the transcurrent movement of the forearc sliver on the Sumatra fault and its continuation in the Andaman Sea. The stress regime for the foreshock group in the Andaman area indicates the normal-fault type striking in NE-SW direction, which agrees with the trend of the spreading center in the Andaman Sea (Curray et al., 1979; Curray, 2005) and thus is consistent with the motion of the forearc block taking up the trench-parallel component of the oblique convergence. A close look at the original data of $P$ and $T$ axes reveals that this group includes several events of strike-slip mechanisms (Fig. 6). The north-south trending strikes of those strike-slip faults are also in harmony with the transcurrent movement of the forearc sliver in the Andaman Sea. The mixture of the two different types of mechanisms is consistent with the formation of the ridge-transform system in this area.

The inverted stress regimes for the aftershock groups in the Nicobar and Sumatra areas refuse similar interpretation. For the Sumatra area, the stress regime indicates vertical or horizontal faults with slip motions incompatible with the expected transcurrent movement of the forearc sliver. Its large distance from the Sumatra fault suggests that the group may represent a type of activity irrelevant to the transcurrent movement of the forearc sliver. Since we cannot find a similar activity in the same hypocentral area before the mainshock, the aftershocks may be due to a strong stress perturbation caused by the mainshock. For the Nicobar area, the stress regime for the aftershock group is of normal fault type. Although its strike trending northsouth agrees with the general trend of tectonic features in this area (Curray et al., 2005), the normal fault with slip directing nearly east-west is in disagreement with the motion taking up the trench-parallel component of the oblique convergence. This group lies between the Andaman foreshock group and the Nicobar foreshock group for which the fault motions were consistent with the transcurrent movement of the forearc sliver. At present we cannot present any idea that can explain the inconsistent fault motions of this group. The hypocenters relocated by Engdahl et al. (2007) suggest that these normal-fault events occur on the West Andaman fault system which lies to the west of the main Sumatra fault system.

In spite of some discrepancies that might have resulted from a strong perturbation due to the mainshock, we conclude that the results of stress inversion show the validity

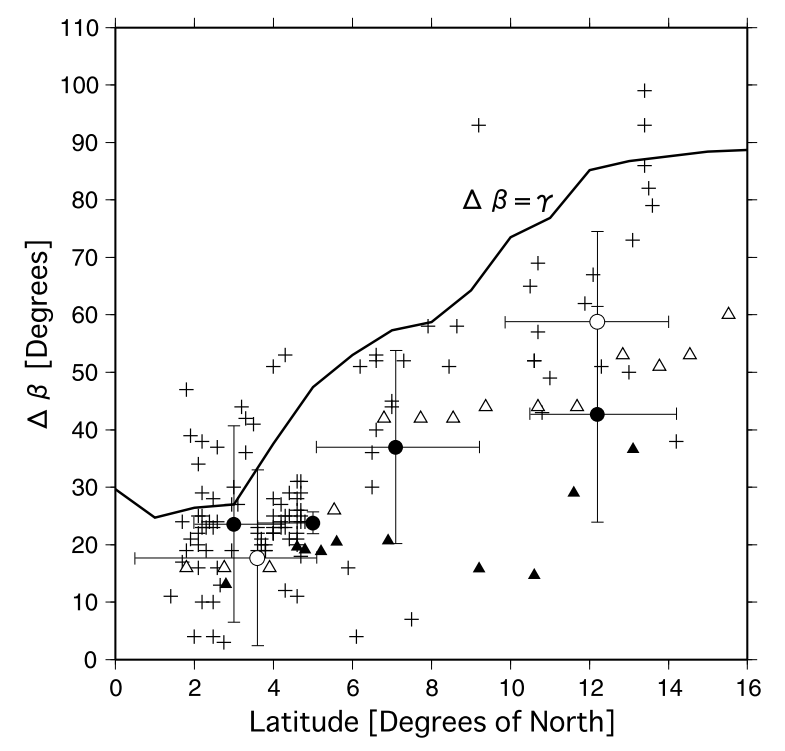

Fig. 7. The SVR $(\Delta \beta)$ plotted against the latitude. The solid (aftershocks) and open circles (foreshocks) indicate the SVRs determined using the slip directions of medium-sized events for each subgroups defined in the text. Error bars represent the standard deviations evaluated from the scatter of the inverted principal stresses for allowable minimum value of $\omega>30$ percents. The horizontal bars attached to the SVRs indicate the range covered by the events of a group. The crosses denote the SVRs determined directly from the slip directions of each event. The open and solid triangles indicate the SVRs determined using the slip directions of the 2004 mainshock by Subarya et al. (2006) and Ammon et al. (2005), respectively. The solid curve represents the SVR for $\Delta \beta=\gamma$.

of the model of oblique convergence in the rupture zone of the 2004 earthquake. This confirmation allows us to step forward and examine the correlation between the slip distribution of the 2004 earthquake and the seismic-slip rate in terms of the model of oblique convergence.

\section{Latitudinal Variation of SVR}

In addition to the slip direction on the megathrust plate boundary, the plate convergence direction is necessary for obtaining the SVR $(\Delta \beta)$. We referred to figure 1 of Subarya et al. (2006) for the plate convergence vectors that were computed from a regional kinematic model given by Bock et al. (2003). The Indo-Australian Plate moves north northeast at a rate of 37 to $39 \mathrm{~mm} /$ year relative to the Sunda shelf along the rupture zone of the 2004 earthquake. Since the convergence vectors do not vary much along the 2004 rupture zone, we adopted a convergence vector near the center of the 2004 rupture, which gives a convergence direction of $\mathrm{N} 20^{\circ} \mathrm{E}$ and a convergence rate of $38 \mathrm{~mm} /$ year, respectively.

The slip direction on the megathrust plate boundary was derived from the inverted principal stresses shown in Fig. 5. Assuming that the axes of three principal stresses correspond to $P, B$ and $T$ axes of the fault plane solution, we calculated the slip direction in the same way as we obtain the rake angle from the vectors of $P, T$ and $B$ axes (Stein and Wysession, 2003). We chose the slip directions for the fault planes dipping continental side. Projection of the slip direction onto the horizontal surface was made by correcting for the dip angle of the fault. The SVRs thus derived via the inverted principal stresses are shown in Fig. 7. The foreshock group in the Nicobar area was eliminated because its stress 
regime is of strike-slip type. The SVRs are each plotted at reduced latitudes, namely the latitudes of points where the trench and the trench normal passing through the epicenters of events intersect. We find no significant difference in the SVRs between the foreshocks and aftershocks. The SVR increases with increasing latitude, indicating that the deflection from the direction of plate convergence gets larger with increasing latitude. In the same figure, we also showed the SVRs that were directly obtained from the slip direction of each event. We discarded the events whose strikes of eastward dipping fault planes deviate largely from local strikes of the trench. The SVRs thus obtained appear to be larger than those derived via the stress inversion, especially at the northern end of the rupture zone. This discrepancy may have resulted from a bias formed during the process of data elimination. Since the dataset used for the stress inversion includes a wider variety of fault plane solutions, the SVRs derived via the stress inversion are considered more robust than the others.

In Fig. 7, we also showed the SVRs determined using the slip directions of the 2004 main shock. One is those determined using the slip directions estimated from the geodetic data (Subarya et al., 2006). The other is those determined using the slip directions estimated from the seismic data (Ammon et al., 2005). The SVRs for the seismic data deviate largely from those for the geodetic data around $10^{\circ} \mathrm{N}$. The SVRs determined using the slip directions of Tsai et al. (2005) are similar to those determined from the geodetic data of Subarya et al. (2006). Except for the discrepancy around $10^{\circ} \mathrm{N}$, the SVRs derived from the slip directions of the 2004 rupture appear to agree with those derived from the medium-sized earthquakes on the whole.

The case $\Delta \beta=0$ corresponds to the case where the slip vector trends completely parallel to the plate convergence vector. The other extreme case, $\Delta \beta=\gamma$, corresponds to the case where the slip vector trends exactly normal to the plate margin. The observed SVRs are distributed close to the curve of $\Delta \beta=\gamma$, deviating significantly from the line of $\Delta \beta=0$. On average, the SVRs are about two-thirds of $\gamma$, indicating that the slip on the megathrust plate boundary is missing a significant fraction of slip parallel to the plate margin. Since the SVRs for foreshocks, aftershocks and the mainshock all follow the similar trend, it is inferred that the same model of oblique convergence works during the interseismic, coseismic and postseismic stages of an earthquake cycle.

\section{Predicted Seismic-Slip Rate and the Slip Distri- bution of the 2004 Rupture}

As defined in (2), the slip rate $s$ on the megathrust plate boundary depends on the plate convergence rate $v$, the obliquity $\gamma$ and the SVR $\Delta \beta$. Figure 8 shows the slip rate calculated for $\Delta \beta$ in Fig. 7. The slip rates for two extreme cases, $\Delta \beta=0$ and $\Delta \beta=\gamma$, are demonstrated for reference. Except for those around $10^{\circ} \mathrm{N}$ obtained from the slip directions of Ammon et al. (2005), the slip rates estimated from the slip directions of the 2004 rupture are similar to those obtained from the medium-sized earthquakes. The predicted slip rates are generally distributed close to the curve for $\Delta \beta=\gamma$, irrespective of the different data sources.

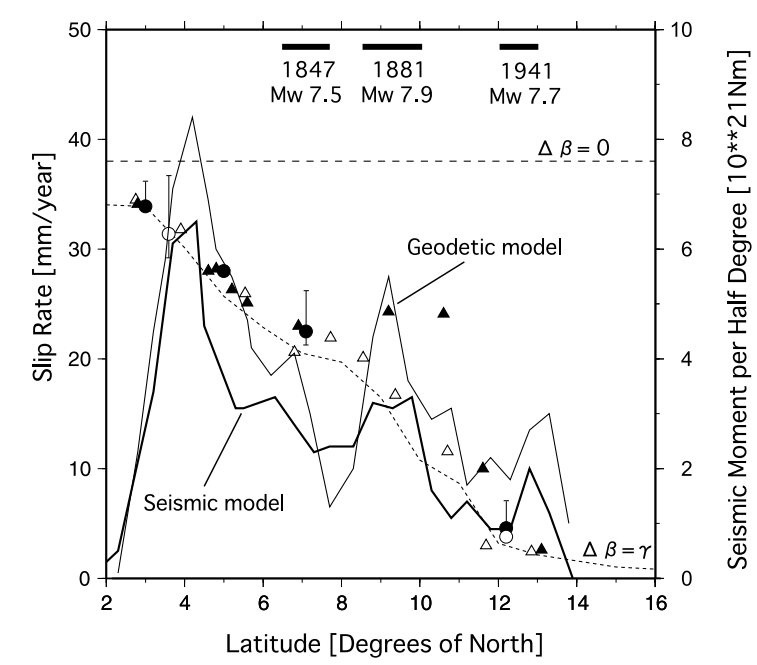

Fig. 8. Latitudinal variation of the slip rate and seismic moment. The solid (aftershocks) and open circles (foreshocks) indicate the slip rates determined from the medium-sized events. Error bars indicate the errors propagating from the errors of SVRs shown in Fig. 7. They are asymmetrical because the slip rate is nonlinear with respect to SVR. The open and solid triangles indicate the slip rates determined using the slip directions of the 2004 earthquake by Subarya et al. (2006) and Ammon et al. (2005), respectively. The observed latitudinal variations of scalar moment released per half degree in latitude is shown by the thick (the seismic model of Ammon et al., 2005) and thin (the geodetic model of Subarya et al., 2006) solid curves. The dashed line labeled $\Delta \beta=0$ corresponds to the case where the slip vector trends completely parallel to the plate convergence vector. The other dashed line labeled $\Delta \beta=\gamma$ corresponds to the case where the slip vector trends exactly normal to the plate margin. Horizontal bars in the upper space indicate the rupture areas of the past historic earthquakes (Bilham, 2005).

Based on the model of oblique convergence, we derived Eq. (4) for predicting the seismic moment rate per unit length along the plate margin. This may be compared with the observed seismic moment per half degree in latitude of the 2004 rupture shown in figure 4 of Subarya et al. (2006). The seismic moment per half degree is obtained by summing the seismic moments of the sub-faults falling in a given range of latitude. Strictly, the seismic moment per half degree does not translate into the seismic moment rate defined by (4) in case where the strike of the trench is not normal to the line of latitude. Equation (4) is based on the assumption that the involved parameters are constant in the direction normal to the trench. However, since the fault segments yielding large slips are generally close to the trench, the latitudes of points where the trench and the trench normal passing through the fault segments of large slip meet do not differ much from the latitudes of the fault segments of large slip themselves. Therefore the above assumption may not seriously be violated even if we equate the latitude defined for the observed seismic moment per half degree in latitude with the latitude defined for the moment rate of (4). Thus we compare the observed seismic moment per half degree of Subarya et al. (2006) with the seismic moment given by

$$
M_{0}=\mu \eta s W t \times \Delta L
$$

where $\Delta L$ denotes the length of half degree in latitude and $t$ is the time during which the seismic moment is accumulated. 
Table 2. Ratios of the observed $\left(M_{0}^{\mathrm{OBS}}\right)$ to the predicted seismic moments $\left(M_{0}^{\mathrm{CAL}}\right)$ for shallow events along the three segments located on the back-arc side. Time period is 30 years from January 1976 through October 2005. $M_{0}^{\mathrm{OBS}}$ in the upper left cell and lower left cell correspond to the time before and after the 2004 mainshock, respectively.

\begin{tabular}{|c|c|c|c|c|c|}
\hline Segment & $\begin{array}{c}v_{s} \\
(\mathrm{~mm} / \text { year })\end{array}$ & $\begin{array}{c}M_{0}^{\mathrm{CAL}}(\mathrm{Nm}) \\
\times 10^{20}\end{array}$ & \multicolumn{2}{|c|}{$\begin{array}{c}M_{0}{ }^{\mathrm{OBS}}(\mathrm{Nm}) \\
\quad \times 10^{19}\end{array}$} & $\begin{array}{c}M_{0}^{\mathrm{OBS}} / \\
M_{0}^{\mathrm{CAL}}\end{array}$ \\
\hline \multirow[t]{2}{*}{ Andaman $\left(10-14^{\circ} \mathrm{N}\right)$} & \multirow[t]{2}{*}{35} & \multirow[t]{2}{*}{3.8} & 1.3 & \multirow[t]{2}{*}{1.5} & \multirow[t]{2}{*}{0.04} \\
\hline & & & 0.18 & & \\
\hline \multirow[t]{2}{*}{ Nicobar $\left(6-10^{\circ} \mathrm{N}\right)$} & \multirow[t]{2}{*}{20} & \multirow[t]{2}{*}{2.2} & 1.9 & \multirow[t]{2}{*}{6.2} & \multirow[t]{2}{*}{0.28} \\
\hline & & & 4.3 & & \\
\hline \multirow{2}{*}{ Sumatra $\left(2-6^{\circ} \mathrm{N}\right)$} & \multirow[t]{2}{*}{14} & \multirow[t]{2}{*}{1.5} & 2.7 & \multirow[t]{2}{*}{2.9} & \multirow[t]{2}{*}{0.19} \\
\hline & & & 0.20 & & \\
\hline
\end{tabular}

Assuming that the variables except $s$ do not vary along the plate margin, we put $\eta=1, \mu=50 \mathrm{GPa}, W=150 \mathrm{~km}$ and $\Delta L=56 \mathrm{~km}$ in (5). The time interval $t$ should be so adjusted that the predicted seismic moment per half degree fits to the observed one. For a time interval of 480 years, the slip rate translates into the seismic moment with its scale indicated on the right-hand side of Fig. 8. We compare this with the observed seismic moments per half degree in latitude given by Subarya et al. (2006). In Fig. 8, the seismic model indicates the one determined from the seismic waveforms (Model of Ammon et al., 2005). The geodetic model is the mean of the two models (Model A and Model B) of Subarya et al. (2006). The seismic moment of the geodetic model is about $30 \%$ larger than that of the seismic model. The additional fault slip is estimated to have accrued in the 1.5 months following the 500-seconds-long seismic rupture (Subarya et al., 2006). In spite of some difference in the absolute value of the seismic moment, both the models show a common feature that the seismic moment decreases from south to north as a whole. This trend correlates well with the seismic moment predicted from the model of oblique convergence. The predicted seismic moment for the time interval of 480 year fits to the average of the seismic and geodetic models at long wavelengths. If the seismic coupling coefficient is assumed to be smaller, the interseismic period would become greater than 480 years accordingly.

\section{Transcurrent Movements of the Forearc Sliver}

Here we determine the forearc slip rate, $v_{s}$, using Eq. (1) and compare it with the seismic moment released by the earthquakes. We divided the vertical fault into three segments, i.e., Andaman segment $\left(10-14^{\circ} \mathrm{N}\right)$, Nicobar segment $\left(6-10^{\circ} \mathrm{N}\right)$ and Sumatra segment $\left(2-6^{\circ} \mathrm{N}\right)$ (Fig. 9). The forearc slip rate for each segment was estimated using the averages of $\gamma$ and $\Delta \beta$ for each segment (Table 2). The forearc slip rates were converted to the seismic moments using the equation,

$$
M_{0}^{\mathrm{CAL}}=\mu v_{s} L W t
$$

where $\mu$ is rigidity, $v_{s}$ the forearc slip rate defined in (1), $L$ and $W$ are the length and the width of the vertical fault and $t$ is the elapsed time. The lengths of the three segments are all about $450 \mathrm{~km}$. Since the locked part of the vertical fault is estimated to be at depths of the order of 10-20 km in the northwestern Sumatra fault (Genrich et al., 2000), we assumed $W=20 \mathrm{~km}$. Using these values and putting $t=30$ years and $\mu=40 \mathrm{GPa}$, we obtained the predicted seismic moments listed in Table 2.

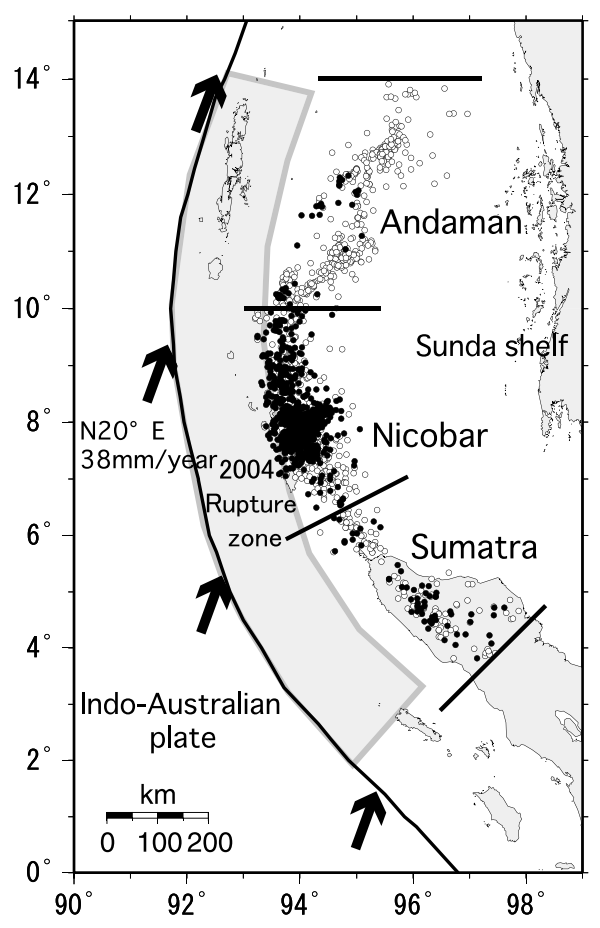

Fig. 9. The epicenter distribution of earthquakes used for obtaining the seismic moments released along the three fault segments on the continental side of the plate margin. Open circles indicate the events before the main shock (1976/1/1-2004/12/26) and solid circles denote the events after the main shock (2004/12/26-2005/10/31).

From the NEIC catalogue we collected the earthquakes occurring in the vicinity of the vertical fault along the northwestern Sumatra fault and its submarine continuation in the Andaman Sea. The time period is the same as set for the study of SVR in the above; i.e., from January 1976 through October 2005. The epicenter distributions of the earthquakes are shown in Fig. 9. In case $M_{\mathrm{w}}$ is not given, we used $M_{\mathrm{s}}$. In case both $M_{\mathrm{w}}$ and $M_{\mathrm{s}}$ are not available, we utilized $m_{\mathrm{b}}$ for estimating the seismic moment of an event. We converted various magnitudes, $M_{\mathrm{w}}, M_{\mathrm{s}}$ and $m_{\mathrm{b}}$ into seismic moments using appropriate conversion formulae (Utsu, 1999). The total seismic moments for each segment are listed in Table 2. As results, the ratios of the observed to the predicted seismic moments are $4 \%$ for the Andaman, $28 \%$ for the Nicobar, and $19 \%$ for the Sumatra segments, respectively. Interpretation of these small ratios is twofold. One is that the residual of the predicted seismic moment is being accumulated for generation of future earthquakes. The other is that the residual was taken up aseismically by the fault creep at shallow depths. Since we have no information on the fault creep at shallow depths, no further discussion can be made about the seismic coupling coefficient for the three segments.

The relatively large ratio for the Nicobar segment is due to the swarm activity after the 2004 rupture. During the foreshock period, released seismic moments are similar among the three segments. However, the seismic moment released after the mainshock is prominent for the Nicobar segment. The other two segments were scarcely activated by the mainshock. We infer that the Coulomb stress change due to the mainshock may not be a direct cause of the swarm 
activity that started about one month later. The time lag suggests that effects associated with a magmatic activity or an afterslip following the mainshok may be involved. Examination of these possibilities must wait for future work.

\section{Discussion and Conclusions}

A good correlation between the predicted slip rate and the slip distribution of the 2004 rupture suggests that the model of oblique convergence holds over a long period of time, roughly over an interseismic period of 500 years. It also suggests that the seismic coupling coefficient has been generally uniform over the rupture zone of the 2004 event. These conditions allow the megathrust plate boundary to accumulate the slip deficit proportional to the slip rate predicted from the model of oblique convergence. Smaller events occurring during the interseismic period can hardly change the dominating latitudinal pattern of the slip deficit. In the event of a gigantic earthquake like the 2004 rupture, the accumulated slip deficit is consumed exhaustively. This is a simple scenario explaining the correlation between the slip distribution of the 2004 rupture and the slip rate predicted from the model of oblique convergence.

The short-wavelength irregularities of the slip distribution of the 2004 rupture may be ascribed to the fluctuation of the frictional strength and the residual stress on the fault. Also, they can be ascribed to the variability of seismic coupling coefficient that has so far been assumed constant along the plate margin. The factors that may affect the seismic coupling, such as the age of the oceanic plate, sediment thickness, and dip angle of the subducted plate, all vary much along the plate margin of the 2004 rupture (Subarya et al., 2006; Engdahl et al., 2007). At present, however, we have no geodetic observations suggesting an along-arc variation of seismic coupling coefficient which can explain the observed irregularities of the slip distribution.

In predicting the forearc slip rate, we assumed the convergence rate of the Indo-Australian Plate relative to the southern portion of the Eurasian Plate (Sunda Shelf) to be $38 \mathrm{~mm} /$ year. This gave the forearc slip rate of $14 \mathrm{~mm} / \mathrm{year}$ for the Sumatra segment (Table 2). Using the convergence rate of $64 \mathrm{~mm} /$ year derived from the Nuvel-1A AustraliaEurasia pole (DeMets et al., 1994), McCaffery et al. (2000) obtained a value of $28 \mathrm{~mm} /$ year for the forearc slip rate on a northwestern section of the Sumatra fault $\left(2-3^{\circ} \mathrm{N}\right)$, which is almost equal to the forearc slip rate estimated from the data of GPS measurements (Genrich et al., 2000). According to figure 1 of Subarya et al. (2006), the convergence rate appears to change from $39 \mathrm{~mm} /$ year to $50 \mathrm{~mm} /$ year off the northwestern Sumatra. If we had used the value of 50 $\mathrm{mm} / \mathrm{year}$ for the convergence rate, the predicted slip rate shown in Fig. 8 and the forearc slip rate listed in Table 2 would have increased by $30 \%$. In a more rigorous analysis, we may have to take into account the variation of the plate convergence rate along the 2004 rupture zone.

In the last two centuries, three major earthquakes are known to have occurred in the rupture zone of the 2004 event (Bilham et al., 2005). They are the 1847 event $\left(M_{\mathrm{w}} 7.5-7.9\right)$ at $7 \pm 1^{\circ} \mathrm{N}$, the 1881 event $\left(M_{\mathrm{w}} 7.9 \pm 0.1\right)$ at $9.26 \pm 0.75^{\circ} \mathrm{N}$, and the 1941 event $\left(M_{w} 7.7 \pm 0.1\right)$ at $12.1 \pm 0.6^{\circ} \mathrm{N}$ (Fig. 8). The estimated slips of these events are 2 to 3 meters. Given the predicted slip rates in Fig. 8, the time intervals between these events and the 2004 rupture should accumulate the slip deficits of $3 \mathrm{~m}, 2 \mathrm{~m}$, and $1 \mathrm{~m}$ for the 1847,1881 , and 1941 events, respectively. During the 2004 rupture, the segments corresponding to those historic events slipped about $6 \mathrm{~m}, 8 \mathrm{~m}$, and $4 \mathrm{~m}$, respectively. The segments slipped much more than the slip deficit accumulated during the last interseismic period. This does not agree with the slip predictable model proposed by Shimazaki and Nakata (1980), in which a constant level of residual shear stress at the start of each interseismic period is assumed. For lack of resolution of slip along the dip direction, especially for the historic earthquakes, it is not certain whether the segments of large slip for the historic earthquakes completely overlap those of the 2004 rupture. Limiting our discussion to the one-dimensional case along the trench, we infer that the fluctuation of the residual shear stress is much larger than have previously been thought. The past historic earthquakes in the western Sunda released only a fraction of the available total stress, though their magnitudes are moderately large. If this is a universal phenomenon, there is a chance that such a gigantic earthquake might occur at other convergent margins where the magnitudes of largest earthquakes ever known are less than the range of 7.5-8.0. Understanding the mechanism of the gigantic earthquakes appears to be quite challenging but is important for mitigating such disasters as brought about by the 2004 earthquake.

Acknowledgments. We thank Hiroo Kanamori and Takeshi Sagiya for reading the manuscript and giving valuable comments. Critical comments by anonymous reviewers were helpful in revision of the manuscript. The figures are prepared using GMT (Wessel and Smith, 1991).

\section{References}

Ammon, C. J., J. Chen, H. Thio, D. Robinson, S. Ni, V. Hjorleifsdottir, H. Kanamori, T. Lay, S. Das, D. L. Helmberger, G. Ichinose, J. Polet, and D. Wald, Rupture process of the 2004 Sumatra-Andaman earthquake, Science, 308, 1133-1139, 2005.

Angelier, J., Inversion of earthquake focal mechanism to obtain the seismotectonic stress-a new method free of choice among nodal planes, Geophys. J. Int., 150, 588-609, 2002.

Bilham, R., R. Engdahl, N. Feldl, and S. P. Satyabala, Partial and complete rupture of the Indo-Andaman plate boundary 1847-2004, Seismol. Res. Lett., 76, 299-311, 2005.

Bock, Y., L. Prawirodirdjo, J. F. Genrich, C. W. Stevens, R. McCaffrey, C. Subarya, S. S. O. Puntodewo, and E. Calais, Crustal motion in Indonesia from Global Positioning System measurements, J. Geophys. Res., 108(B8), 2367, doi:10.1029/2001JB000324, 2003.

Curray, J. R., Tectonics and history of the Andaman Sea region, J. Asian Earth Sci., 25, 187-232, 2005.

Curray, J. R., D. G. Moore, L. A. Lawver, F. J. Emmel, R. W. Raitt, M. Henry, and R. Kieckhefer, Tectonics of Andaman Sea and Burma, AAPG Mem., 29, 189-198, 1979.

DeMets, C., R. G. Gordon, D. F. Argus, and S. Stein, Effects of recent revisions to the geomagnetic reversal time scale on estimates of current plate motions, Geophys. Res. Lett., 21, 2191-2194, 1994.

Dziewonski, A. M., T. A. Chou, and J. H. Woodhouse, Determination of earthquake source parameters from waveform data for studies of global and regional seismicity, J. Geophys. Res., 86, 2825-2852, 1981.

Engdahl, E. R., A. Villasenor, H. R. Deshon, and C. H. Thurber, Teleseismic relocation and assessment of seismicity (1918-2005) in the region of the $2004 \mathrm{Mw}$ 9.0 Sumatra-Andaman and $2005 \mathrm{Mw} 8.6$ Nias Island great earthquakes, Bull. Seism. Soc. Am., 97(1A), S43-S61, 2007.

Fitch, T. J., Plate convergence, transcurrent faults and internal deformation adjacent to southeast Asia and the western Pacific, J. Geophys. Res., 77, 4432-4460, 1972. 
Genrich, J. F., Y. Bock, R. McCaffrey, L. Prawirodirdjo, C. W. Stevens, S. S. O. Puntodewo, C. Subarya, and S. Wdowinski, Distribution of slip at the northern Sumatran fault system, J. Geophys. Res., 105(B12), 2832728342, doi:10.1029/2000JB900158, 2000.

Kanai, T., T. Miyamura, Y. Oishi, and A. Makinouchi, CHIKAKU DB/CAD: A System for Modeling 3D Tectonic Structure, ComputerAided Design and Applications, Proc. CAD'05 Conference, Bangkok, Thailand, 20-24 June, 2005, 2, 403-410, 2005.

Lay, T., H. Kanamori, C. J. Ammon, M. Nettles, S. N. Ward, R. C. Aster, S. L. Beck, S. L. Bilek, M. R. Brudzinski, R. Butler, H. R. DeShon, G. Ekstrom, K. Satake, S. Sipkin, The great Sumatra-Andaman earthquake of 26 December 2004, Science, 308, 1127-1133, 2005.

McCaffrey, R., Slip vectors and stretching of the Sumatran fore arc, Geology, 19, 881-884, 1991.

McCaffrey, R., On the role of the upper plate in great subduction zone, $J$. Geophys. Res., 98, 11953-11966, 1993.

McCaffrey, R., P. C. Zwick, Y. Bock, L. Prawirodirdjo, J. F. Genrich, C. W. Stevens, S. S. O. Puntodewo, and C. Subarya, Strain partitioning during oblique plate convergence in northern Sumatra: Geodetic and seismologic constraints and numerical modeling, J. Geophys. Res., 105, 28363-28376, 2000

Michel, G. W., M. Becker, D. Angermann, C. Reigber, and E. Reinhart, Crustal motion in E- and SE-Asia from GPS measurements, Earth Planets Space, 52, 713-720, 2000.
Paul, J., R. Bürgmann, V. K. Gaur, R. Bilham, K. M. Larson, M. B. Ananda, S. Jade, M. Mukal, T. S. Anupama, G. Satyal, and D. Kumar, The motion and active deformation of India, Geophys. Res. Lett., 28(4), 647-650, doi:10.1029/2000GL011832, 2001.

Shimazaki, K. and T. Nakata, Time predictable recurrence model for large earthquakes, Geophys. Res. Lett., 7, 279-282, 1980.

Stein, S. and M. Wysession, An Introduction to Seismology, Earthquakes and Earth Structure, pp. 498, Blackwell Publishing, Massachusetts, 2003.

Subarya, C., M. Chlieh, L. Prawirodirdjo, J. Avouac, Y. Bock, K. Sieh, A. J. Meltzner, D. H. Natawidjaja, and R. McCaffrey, Plate-boundary deformation associated with the great Sumata-Andaman earthquake, Nature, 440, doi:10.1038/nature04522, 2006.

Tsai V. C., M. Nettles, G. Ekström, A. M. Dziewonski, Multiple CMT source analysis of the 2004 Sumatra earthquake, Geophys. Res. Lett., 32, L17304, doi:10.1029/2005GL023813, 2005.

Utsu, T., Critical Review of Researches on Earthquake Activity, pp. 876, Tokyo University Press, Tokyo, 1999.

Wessel, P. and W. H. F. Smith, Free software helps map and display data, EOS Trans. AGU, 72, 441, 1991.

M. Oishi (e-mail: oishi_m@seis.nagoya-u.ac.jp) and T. Sato (e-mail: tamao@cc.hirosaki-u.ac.jp) 